\title{
A Detailed Study On Different Generations Of Solar Cell Technologies With Present Scenario Of Solar PV Efficiency And Effect Of Cost On Solar PV Panel
}

\author{
Adithya Ballaji ${ }^{1}$, Ananda $\mathrm{MH}^{2}$, K Narayana Swamy ${ }^{3}$, Sujo Oommen ${ }^{4}$, Burri Ankaiah ${ }^{5}$ \\ Assistant Professor, School of EEE, REVA University ${ }^{1,2,4,5}$ \\ Associate Professor, School of EEE, REVA University ${ }^{3}$ \\ Email: adithya.ballaji@reva.edu.in ${ }^{1}$, ananda.mh@reva.edu.in ${ }^{2}$
}

\begin{abstract}
The need for the unlimited source of energy has always been the area of concern as the efficiency of the available energy is still a major issue. As we have known that solar energy is abundantly available is nature but the use of solar energy is limited due the efficiency of the panels. The Photovoltaic efficiency is one the major areas for research and concern too if the aim for unlimited source of energy is to be realized. The paper presents a detailed study on the available and latest trends in solar cell technologies along with the present scenario of Solar PV efficiency through NREL data and the change and impact of price drop on solar PV panel. This paper can also be used a reference for new and budding researchers in the field of Solar cell technology.
\end{abstract}

Keywords- Types of solar cells, III-V multi-junction cell, Perovskite Solar cell, Best Research PV efficiency, NREL.

\section{INTRODUCTION}

The awareness for clean and sustainable source of energy is at its peak with the attenuation of conventional sources of energy like oil, gas and coal. And the need for unlimited source of power has become reality. Solar energy is one such source of energy which is abundantly available in nature and is capable of generating unlimited power. One of the barrier which stands in the way of solar becoming a source of unlimited energy is the efficiency of solar PV modules. A gigantic amount of work on improving the efficiency of solar cell technology is being carried out all around the world. To start with a solar cell (photovoltaic cell or photoelectrical \} phenomenon cell) is also a solid state device which has the ability to converts the light energy from the sun to directly into electricity by the photovoltaic phenomenon impact. The energy of sunshine is transmitted by photons-small packets or quantum's of sunshine. Current is stored in electromagnetism fields, that successively will build a current of electrons flow. A key operation of photovoltaic cell can be delineated as it absorbs light with efficiency then separates charge (electrons from "holes") creates electrical current and voltage when well-lighted thus acts as a sort of battery underneath daylight. From this we will protract the 3 indispensable necessities for the task of operating a photovoltaic cell i.e. initially it wants the absorption of sunshine, generating either electron-hole pairs or exactions, second the separation of charge carriers of opposite sorts and eventually the separate extraction of these carriers to an external circuit. Figure 1 shows the essential structure of a semiconducting silicon material cell. Photovoltaic based phenomenon power was initially discovered by a French man of science Edmond Becquerel in 1839.
The primary operating Solar or Photovoltaic cell was with success created by Charles Fritts in 1882. It had been product of skinny sheets of selenium and coated with gold. The utilization of Solar panels for generating electricity and heat looks comparatively like new development; it's really been used earlier to generate power since early $1900^{\text {ces }}$. In 1954 Bell laboratory mass created the first crystal silicon semiconducting material photovoltaic cell. The bell PV regenerated $4 \%$ of the sun's energy into electricity a rate that was thought-about the leading edge in energy technology. Heir scientists Daryl M. Chapin created a silicon-based Photovoltaic cell with potency of concerning efficiency of $6 \%$.Scientists continuing to reinvent and increased on the look of the first photovoltaic cell and were ready to turn out a photovoltaic cell that was capable of putting $20 \%$ return electricity rate or efficiency. within the late $1900^{\circ \mathrm{s}} \mathrm{s}$ as awareness grew within the science community concerning the consequences of world global warming and therefore the want for renewable energy sources, scientists continuing to refine the semiconducting silicon material PV and by early 2000 they were ready to build a photovoltaic cell with $24 \%$ electricity return or efficiency . In barely seven years scientists were once more ready to increase the electricity outcome of semiconducting silicon material PV cell exploitation time and space age material. 


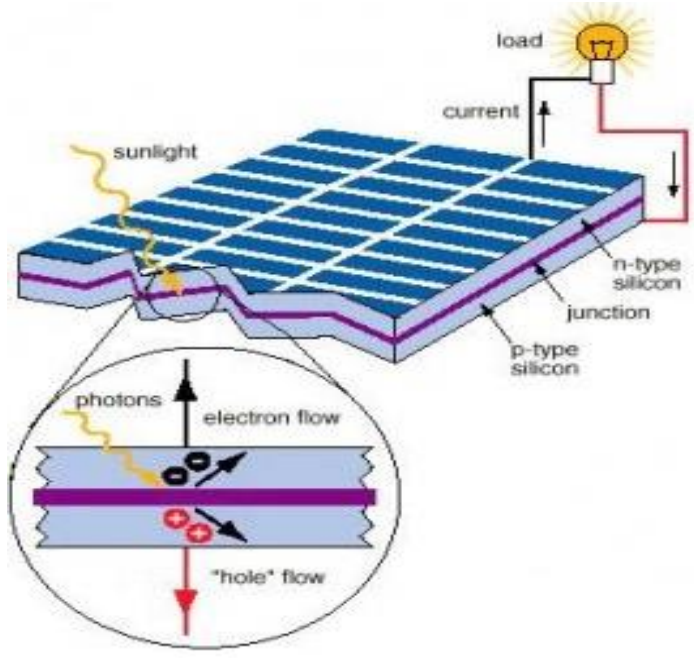

Fig. 1 Basic Structure of a silicon cell

By 2007, trendy semiconductor silicon PV solar cells were operational with $28 \%$ (twenty eighth) electricity return or efficiency. There are a large variants of PV cell technologies on the market nowadays and a lot of applications. The foremost economical solar panels on the market nowadays have efficiency ratings as high as $22 \%$, whereas the bulk of panels vary from $15 \%$ to $17 \%$ efficiency rating. SunPower panels are familiar for being the foremost efficient solar panel whole out there on the market. Although they'll go with high price. SunPower can usually be the patron favorite for anyone involved and concerned about efficiency as a primal metric of interest. Here are the highest 5 best solar panel makers hierarchal ranked the very best efficiency solar panel they need to offer:

(1) SunPower_(22.2\%)

(2) Panasonic $(21.6 \%)$

(3) LG $(21.1 \%)$

(4) Hanwha Q CELLS (19.6\%)

(5) Solaria $(19.4 \%)$

\section{CLASSIFICATION OF PV CELL}

Solar cells are generally named after the semiconductor material they're fabricated from. These materials should have sure characteristics so as to soak up sunlight. Some cells are unit designed to handle sunlight that reaches the Earth's surface, whereas others are unit optimized to be used in space. Solar cells will be fabricated from just one single layer of light-absorbing material (singlejunction) or use multiple physical configurations (multi-junctions) to acquire advantage of assorted absorption and charge separation mechanisms. Solar cells will be classified into first, second and third generation cells. The primary generation cells-also known as typical, ancient or wafer-based cells-are fabricated from crystalline silicon the commercially predominant PV technology, that has materials like poly-silicon and mono-crystalline silicon. Second generation cells are thin film solar cells, that embrace amorphous silicon, CdTe and CIGS cells and are commercially vital in utility-scale Photovoltaic power stations, building integrated photovoltaic's or in little standalone facility. The second generation of Solar cells includes variety of thin-film technologies usually delineate as rising photovoltaic's - most of them haven't nevertheless been commercially applied and are still within the analysis or development section. Several use organic materials, usually organo-metallic compounds moreover as inorganic substances.

Despite the actual fact that their efficiencies had been low and therefore the stability of the absorbent material was usually too short for industrial applications, there's plenty of analysis invested into these technologies as they promise to attain the goal of manufacturing inexpensive, high-efficient solar cells. Third-generation Photovoltaic phenomenon cells are solar cells that are ready to overcome the Shockley-Queisser limit of $31-41 \%$ power efficiency for single band-gap solar cells. This includes a spread of alternatives to cells product of semi conductive p-n junctions ("first generation") and thin film cells ("second generation"). Common third-generation systems embody multi-layer ("tandem") cells product of amorphous semiconductor or gallium arsenide, whereas additional theoretical developments embody frequency conversion, (i.e. changing the frequencies of sunshine that the cell will not use to light frequencies that the cell can use - so manufacturing additional power), hot-carrier effects and alternative multiple-carrier ejection techniques developing photovoltaic cells include:

(1) Copper zinc tin sulfide solar cell (CZTS), and derivates CZTSe and CZTSSe

(2) Dye-sensitized solar cell, also known as "Grätzel cell"

(3) Organic solar cell

(4) Perovskite solar cell

(5) Quantum dot solar cell

The achievements within the analysis and research of Perovskite cells, especially, have received tremendous attention within the public as their analysis efficiencies recently soared on top of $20 \%$. They additionally provide a large spectrum of inexpensive applications. Additionally, another upcoming technology, concentrator photovoltaic's (CPV), uses high-efficient, multi-junction solar cells together with optical lenses and a tracking system. The classification of various solar cell technology supported with different generation of Solar cell is listed in Figure 2. 
International Journal of Research in Advent Technology, Vol.7, No.4, April 2019

E-ISSN: 2321-9637

Available online at www.ijrat.org

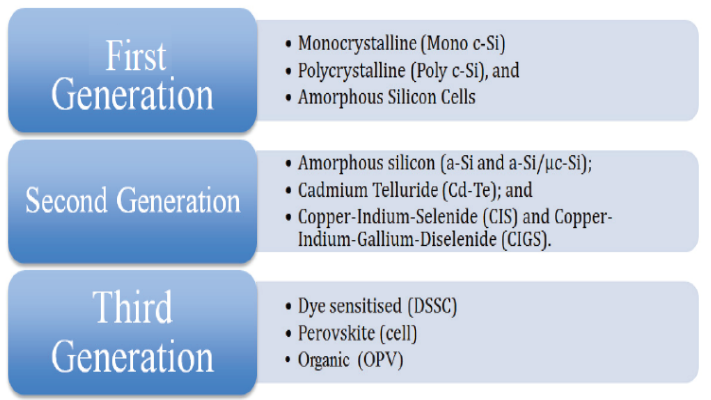

Fig. 2 Classification of PV cells

\subsection{First generation - Crystalline Silicon}

Silicon may be a semiconductor material illustrated appropriate for PV applications, with energy band gap of $1.1 \mathrm{eV}$. Crystalline silicon is that material ordinarily utilized in the PV trade, wafer-based C-Si PV cells and modules dominate the present market. Crystalline silicon cells are classified into 3 sorts as:

A. Mono-crystalline (Mono c-Si).

B. Poly-crystalline (Poly c-Si), or multicrystalline (mc-Si).

C. Amorphous silicon cells

Commercial production of $\mathrm{C}-\mathrm{Si}$ modules began in 1963 once sharp Corporation of Japan started manufacturing industrial PV modules and put in a 242 W PV module on a light house, the world's largest industrial PV installation at that point. Crystalline silicon technologies accounted for regarding $87 \%$ of worldwide PV sales in 2010. The potency of crystalline silicon modules ranges from $14 \%$ to $19 \%$. Whereas a mature technology continued value reductions through enhancements in materials and producing processes. If the market continues to grow,

$\lim _{t \rightarrow \infty} \frac{N(i, t)}{t}=q_{i}$

a variety of high-volume makers to emerge.

\subsection{Mono-Crystalline silicon}

Mono - crystalline silicon cells as shown in Fig.4 have the very best degree of efficiency of the 3 most typical technologies up to $20 \%$. Production: could be a sort of PV cell material factory-made from single crystal silicon structure high purity silicon rods (ingots) are extracted from a solid then cutted into thin slices (wafers) that are then processed into PV cells. Expected period of those cells is often twenty five thirty years. [2]
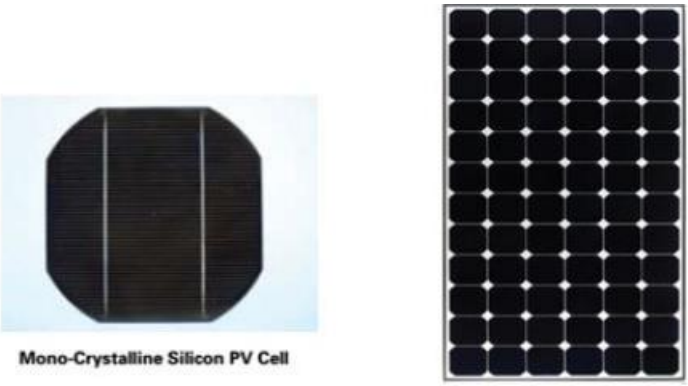

Fig. 4 Mono Crystalline cell and module

\subsection{Poly-Crystalline silicon}

The Silicon molecular structure consists of many smaller set or grains of crystals that introduce boundaries between them as Shown in Fig. 5 .

Production: the assembly of those cells is additionally economical and highly efficient compared to mono crystalline. Creating the photovoltaic cell to own a lower potency. In contrast to mono-crystalline silicon, the Silicon here is solid in blocks. Once it hardens, it leads to crystal structures of various sizes on whose border defects occur. These defects scale back the degree of efficiency, the lab efficiency: $18 \%$ to $23 \%$ and Production range: $14 \%$ to $17 \%$

\section{Advantages:}

- Has been entrenched and test technology

- The efficiency is stable

- Cost wise it is less expensive then single crystal silicon

- Due to presence of square cells it allows efficient packing density

\section{Disadvantages:}

- Expensive materials are used

- Due to slicing of wafers wastage is more

- Slightly less efficient than single crystal

\subsection{Amorphous silicon cell}

Amorphous Silicon (a-Si) PV modules were the primary and first thin film PV modules to be commercially created. Amorphous silicon (a-Si) is that the non-crystalline sort of silicon. It's the foremost well developed of the thin film technologies having been on the market for over fifteen years. It's widely utilized in pocket calculators; however it additionally powers some personal homes, buildings, and remote facilities. It's the non-crystalline sort of Silicon. Amorphous silicon cell contains solely regarding $1 / 300$ th the number of active material during a crystalline-silicon cell. In its simplest kind, the cell structure includes a single sequence of p-i-n layers. The figure 6 shows the structure of the Amorphous silicon. 


\section{Available online at www.ijrat.org}

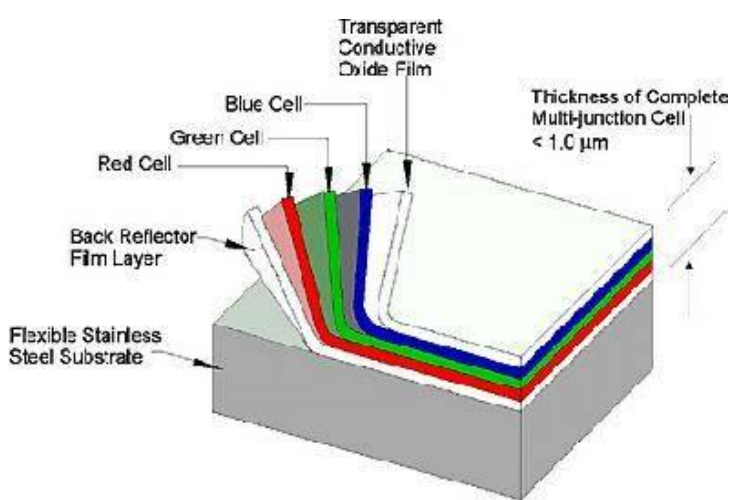

Fig. 6 Amorphous silicon structure

While crystalline $\mathrm{Si}$ achieves a yield of regarding $18 \%$ amorphous solar cells' yield remains at around $7 \%$. The low potency rate is part because of the StaeblerWronski result, that manifests itself within the $1 \mathrm{st}$ hours once the panels are exposed to sunlight, and ends up in a decrease within the energy yield of an amorphous Silicon panel from $10 \%$ to $7 \%$. A German research worker from Delfth University of Technology has presented a way to raise the energy output of amorphous silicon solar panels from around $7 \%$ to $10 \%$. In his research, Gijs van Elzakker investigated diversifications within the production processes of amorphous Silicon modules to extend the output with none further prices victimization using Silane Gas to cut back the Staebler-Wronski result. The principal advantage of amorphous Si solar cells is their lower producing prices, that makes these cells highly price competitive.

\section{SECOND GENERATION SOLAR PV CELL}

The second generation Solar cells additionally known as thin film solar cells is considerably cheaper to supply than 1st generation cells however lower efficiencies have. Second generation technologies are gaining market share since 2008 . They are mounted on a glass substrate. the good advantage of second generation thin film PV cell, in conjunction with low price is their flexibility. The efficiencies have been lower compared to $1 \mathrm{st}$ generation cells. Thin film technologies cut back the quantity of fabric needed in making a PV cell. The foremost second generation materials embody amorphous silicon, microcrystalline silicon, Cadmium Telluride (CdTe) and Copper Indium Gallium Selenide (CIGS).the massive appeal of those sorts of solar cells is that they're more costeffective (below \$1.00/watt to produce).

\subsection{Amorphous silicon solar cell}

Along with CdTe PV cells are the foremost developed and wide popular thin - film solar cells. Amorphous silicon may be deposited on low cost and extremely massive substrates ( up to $5.7 \mathrm{~m}^{2}$ of glass ) supported with continuous deposition techniques, so significantly reducing the production costs. While companies also are developing lightweight, versatile A-Si modules utterly appropriate for flat and recurvate surfaces, amorphous silicon module efficiencies are within the range of $4 \%$ to $8 \%$. Terribly tiny cells at laboratory level could reach efficiencies of $12 \%$. See cell in Fig. 7.

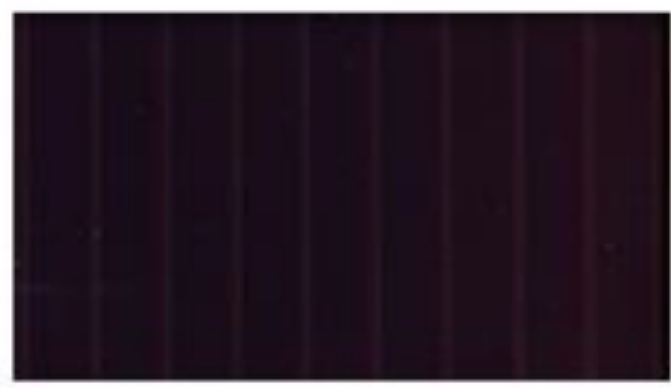

Fig.7 Amorphous solar cell

The main disadvantage of amorphous silicon solar cells is that they suffer from a significant reduction in power output over time As the sun degrades their performance. Even thinner layers could increase the electric field strength across the material and provide stability and less reduction in power output, but this reduces light absorption and hence cell efficiency. A notable variant of amorphous silicon solar cells is the multi-junction thin-film silicon $(\mathrm{a}-\mathrm{Si} / \mu \mathrm{c} \mathrm{Si})$ Which consists of A-Si cell with additional layers of $\mathrm{A}-\mathrm{Si}$ and micro crystalline silicon ( $\mu \mathrm{c}-\mathrm{Si}$ ) applied onto the Substrate.

The advantage of the $\mu \mathrm{c}$ - Si layer is that it absorbs more light from the red and near infrared part of the light spectrum, thus increasing the efficiency by up to $10 \%$. The thickness of the $\mu \mathrm{c}-\mathrm{Si}$ layer is in the order of $3 \mu \mathrm{m}$ and makes the cells thicker and more stable. The current deposition techniques enable the production of multi-junction thin-films up to $1.4 \mathrm{~m}^{2}$.

The main disadvantage of amorphous silicon solar cells is that they suffer from a big reduction in power output over time ( $15 \%$ to $35 \%$ ). Because the sun degrades their performance. Even thin layers may increase the electrical field intensity across the fabric and supply stability and fewer reduction in power output, however this reduces light absorption and thus cell efficiency. A notable variant of amorphous silicon solar cells is that the multi-junction thin-film silicon (a - $\mathrm{Si} / \mu \mathrm{c} \mathrm{Si}$ ) that consists of A-Si cell with extra layers of $\mathrm{A}-\mathrm{Si}$ and small crystalline silicon $(\mu \mathrm{c}-\mathrm{Si})$ applied onto the Substrate.

\subsection{Cadmium Telluride Solar Cell (CdTe)}

A Cadmium Telluride Solar Cell uses a thin layer of semiconducting Cadmium Telluride (CdTe) to absorb and convert sunlight into electricity. The Cadmium present in the cells would be toxic if released. P- Type CdTe is sandwiched with n-type Cadmium Sulfide to form p-n junction. As of 2013, CdTe cell efficiency approached $19.6 \%$ in the laboratory.

\subsection{Copper Indium Gallium Selenide Solar Cell (CIGS)}

Copper Indium Gallium Selenide (CIGS) is a direct band gap material. Co- evaporation and sputtering methods are used to fabricate CIGS thin film solar 
cell. The heterojunction is formed between the semiconductors CIGS and $\mathrm{ZnO}$, separated by a thin layer of CdS. As the absorption coefficient of CIGS is very high, it strongly absorbs sunlight. The efficiency of CIGS solar cell is $20 \%$ which is the record to date for any thin film solar cell.

\subsection{Gallium Arsenide multi-junction Solar Cell (CIGS)}

For special applications like satellites and house exploration, high efficiency multi-junction cells were developed. The multi-junction solar cells also are known as tandem solar cells. They contains multiple thin films. As an example a triple junction cell could contains the semiconductors Gallium arsenide (GaAs), Germanium (Ge) and Gallium Indium diphosphate (GaInP2). The semiconductors are chosen to soak up nearly the complete solar spectrum, therefore generating electricity from the maximum amount of the solar power as attainable. GaAs primarily based multijunction star cells have established to be the foremost economical solar cells on the laboratory scale. The efficiency of triple junction cell has reached $42.3 \%$. But this efficiency is gained at the value of multiplied complexness and producing price. The high price and price to performance ratio of multi-junction solar cells have restricted their use.

\section{THIRD GENERATION SOLAR PV CELL}

Third generation technologies advances intend to upgrade poor electrical execution of second generation (thin film technologies) while keeping up exceptionally low generation costs. For the most part, third era cells incorporate sunlight based cells that needn't bother with the p-n intersection important in customary semiconductor, silicon-based cells. Third era contains a wide scope of potential sun oriented advancements including polymer sun powered cells, nanocrystalline cells, and dye-sensitized solar cells. A color sharpened sun based cell (DSSC, DSC or DYSC ) is an ease sun based cell having a place with the gathering of flimsy film sunlight based cells.It depends on a semiconductor framed between a photograph sharpened anode and an electrolyte, a photo electrochemical framework. A cutting edge DSSC appeared in fig(2) is made out of a permeable layer of titanium dioxide nanoparticles, secured with a sub-atomic color that retains daylight. The titanium dioxide is submerged under an electrolyte arrangement, above which is a platinum-based impetus. As in an ordinary antacid battery, an anode (the titanium dioxide) and a cathode (the platinum) are put on either side of a fluid conductor (the electrolyte). Daylight goes through the straightforward cathode into the color layer where it can energize electrons that at that point stream into the titanium dioxide. The electrons stream toward the straightforward cathode where they are gathered for controlling a heap. In the wake of coursing through the outside circuit, they are re-brought into the cell on a metal cathode on the back, streaming into the electrolyte. The electrolyte at that point transports the electrons back to the color particles. In the DSSC, the main part of the semiconductor is utilized exclusively for charge transport, the photoelectrons are given from a different photosensitive color. Charge partition happens at the surfaces between the color, semiconductor and electrolyte. The color particles are very little (nanometer measured), so as to catch a sensible measure of the approaching light the layer of color atoms should be made genuinely thick, a lot thicker than the particles themselves. To address this issue, a nano-material is utilized as a platform to hold expansive quantities of the color particles in a 3-D lattice, expanding the quantity of atoms for some random surface region of cell. Generally speaking pinnacle control change proficiency for current DSSCs is about $11 \%$.Current record for models lies at $12.3 \%$.

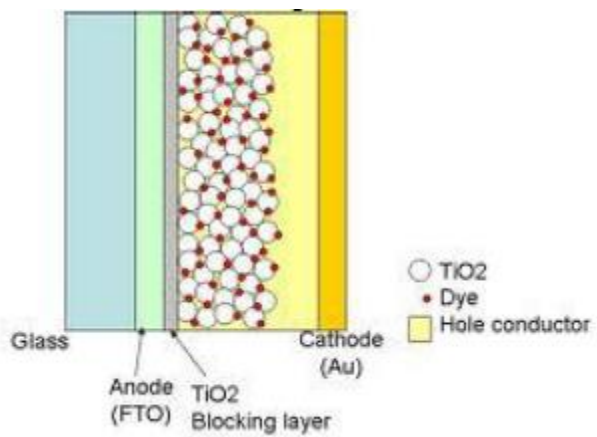

Fig. 8 dye-sensitized solar cell

\subsection{Quantum dot solar Cell (QDSCs)}

Are based off of the Gratzel cell, or dye-sensitized solar cell as shown in Figure 8, architecture but employ low band gap semiconductor nanoparticles, also called quantum dots (such as CdS, CdSe, Sb2S3, $\mathrm{PbS}$, etc.), instead of organic or organometallic dyes as light absorbers. (nc-Si) has about the same bandgap as c-Si, the nc-Si and a-Si can advantageously be combined in thin layers, creating a layered cell called a tandem cell. The top cell in a-Si absorbs the visible light and leaves the infrared part of the spectrum for the bottom cell in nc-Si.

4.2. Organic solar cells and polymer solar Cell

Are built from thin films (typically $100 \mathrm{~nm}$ ) of organic semiconductors including polymers, such as polyphenylene vinylene and small-molecule compounds like copper phthalocyanine (a blue or green organic pigment) and carbon fullerenes and fullerene derivatives such as PCBM. Energy conversion efficiencies achieved to date using conductive polymers are low compared to inorganic materials. However, it has improved quickly in the last few years and the highest NREL (National Renewable Energy Laboratory) certified efficiency has reached 8.3\% for the Konarka Power Plastic. In addition, these cells could be beneficial for some applications where mechanical flexibility and disposability are important. These devices differ from inorganic semiconductor solar cells in that they do not rely on the large built-in 
International Journal of Research in Advent Technology, Vol.7, No.4, April 2019

E-ISSN: 2321-9637

Available online at $w w w . i j r a t . o r g$

electric field of a PN junction to separate the electrons and holes created when photons are absorbed. The active region of an organic device consists of two materials, one which acts as an electron donor and the other as an acceptor. When a photon is converted into an electron hole pair, typically in the donor material, the charges tend to remain bound in the form of an exciton, and are separated when the exciton diffuses to the donor-acceptor interface. excitons are broken up into free electrons-hole pairs by effective fields. The effective field are set up by creating a heterojunction between two dissimilar materials. Effective fields break up excitons by causing the electron to fall from the conduction band of the absorber to the conduction band of the acceptor molecule. It is necessary that the acceptor material has a conduction band edge that is lower than that of the absorber material.The short exciton diffusion lengths of most polymer systems tend to limit the efficiency of such devices. Nanostructured interfaces, sometimes in the form of bulk hetero-junctions, can improve performance. [3]

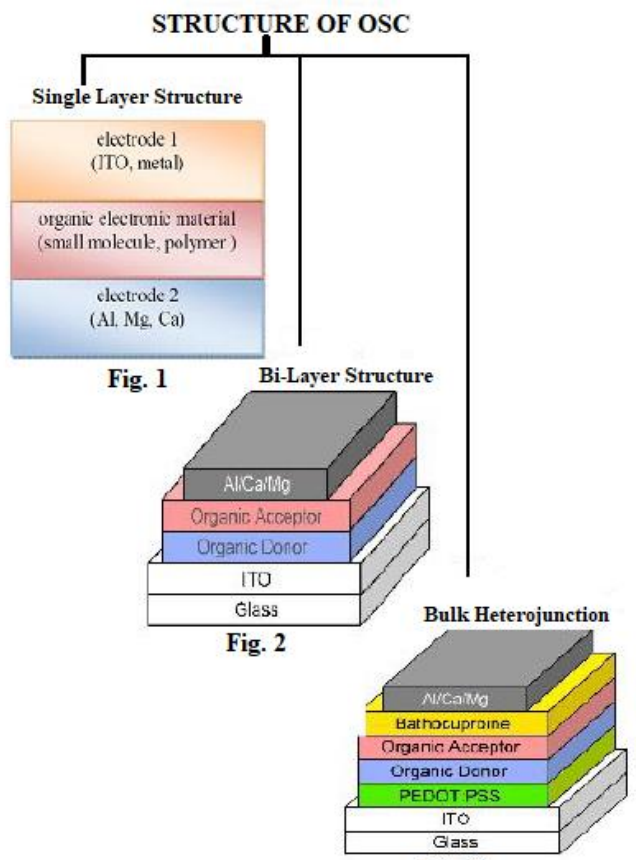

Fig. 3

Fig. 9 Structure of OSC

As shown in fig (1) single layer structure of OSC consists of - Organic material is sandwiched between two electrodes, One electrode is transparent, Organic material absorbs/emits light (OPV/OLED). As shown in fig (2) bilayer OSC structure consists of - Two different organic materials, Exciton dissociation at the interface, Power conversion efficiency $>1 \%$ is possible. Structure of bulk heterojunction OSC shown in fig (3) consists of -

Bathocuproine:

- Exciton blocking layer

- Hole blocking layer

- Prevents metal diffusion into acceptor

\section{PEDOT: PSS:}

- Smoothes rough ITO surface

- Exciton blocking layer

OSC Advantages:

- Low temperature, low energy processing

- Low material requirement

- Relatively cheap in production and purification.

- Can be used on flexible substrate.

- Materials can be tailored for the demand

- Can be shaped or tinted to suit architectural applications.

- Low manufacturing cost

- Utilization of eco friendly materials

- Scalable manufacturing processes for large area Organic solar cells (OSC) are flexible, semitransparent and relatively inexpensive to produce.

OSC Disadvantages

- Low efficiency

- Unproven technology

- Limited lifetime/ stability issue

\section{LIMITATIONS OF DIFFERENT GENERATION'S SOLAR CELLS}

For renewable energies, like solar energy, to compete with fossil fuels, there are two challenges to be met:

a. increased efficiencies

b. reduce production costs

Generally 1st generations solar cell based on Silicon (Si) solar cell. Though this technology has high conversion efficiency but the availability of Silicon is intricate because of its high cost. Also the fabrication process of the silicon based solar cell is complex. Several issues affect the efficiency of solar cells:

- The energy of the photons hitting the solar cell is less than the band gap, so the light cannot be converted

Into electricity and is lost.

- The energy of the incoming photons is greater than the band gap, so the excess energy is lost as heat.

The Fermi levels of both n-type and p-type silicon are always inside the band gap of silicon so the opencircuit voltage is smaller than the band gap.

2nd generation solar cells based on thin film solar cells. Some advantages are illustrated below.

- It has high absorption co-efficient

- It can occupy both vacuum and non-vacuum process.

- Lower cost in comparison of Si based solar cell.

- Low cost substrate (Cu tape)

Disadvantages are:

- Environment Contamination starts from fabrication process.

- Materials are hard to find.

Advantages of 3rd generation solar cells are (polymer):

- Raw materials are easy to find 
- Easier fabrication process rather than other two technologies

- Cost is minimal

Disadvantages of 3rd generation solar cells (organic):

- Liquid electrolyte (low temperature) High cost, Ru (dye) and Pt (electrode)

\section{SOLAR PANEL COST AND EFFICIENCY}

Solar panel technology has been around in some form for a long time - Bell Labs invented the first useful solar cell more than 60 years ago, and scientists have known for centuries that the sun can be used to produce energy. However, it's only in the last ten years or so that solar photovoltaic's (PV) has really taken off as a renewable energy source. There are two major factors influencing the technology's growth: the steady improvement of both solar panel cost and solar panel efficiency over time. The cost of solar is dropping across the nation

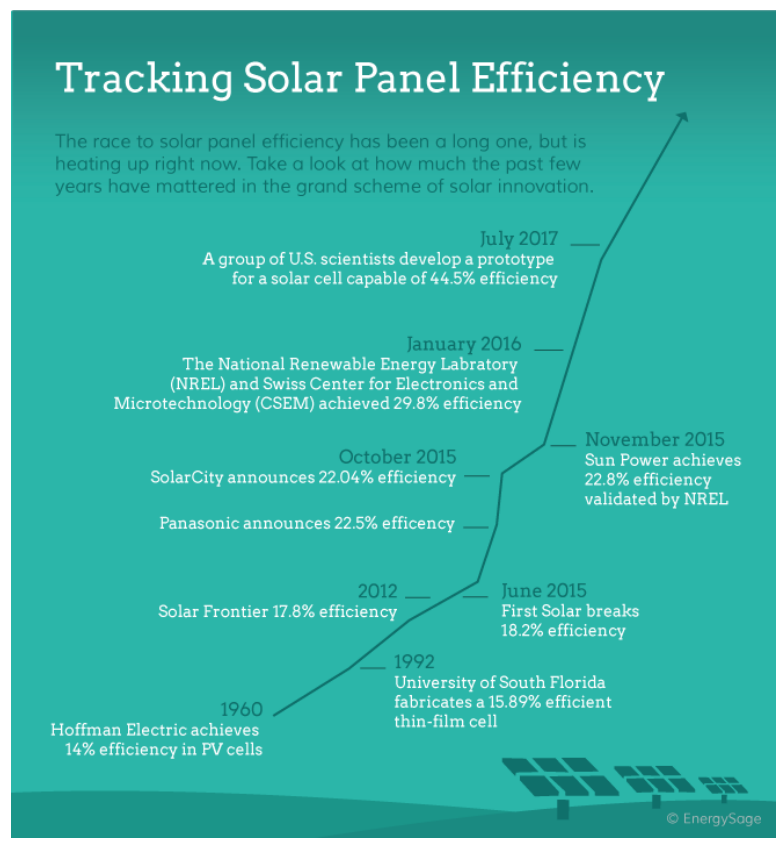

Fig. 10 Tracking Solar cell Efficiency

\section{COST OF SOLAR PANELS OVER TIME: A TALE OF FALLING PRICES}

10 years ago, in 2009, the cost of a solar panel installation was $\$ 8.50$ per watt. The solar industry today looks very different: in addition to solar panel efficiency increasing dramatically, solar panel producers have significantly improved their manufacturing processes. Solar installers, too, can deploy solar PV across the United States more efficiently now than they could ten years ago. The result: the price of solar has fallen by over 60 percent, to just \$3.05/watt as depicted in Figure 11

There's evidence that solar prices are continuing to fall. From the second half of 2018 to the first half of 2019 , prices featured in quotes to homeowners on the EnergySage Solar Marketplace fell by $2.2 \%$.
Changes in solar panel cost over time can be explained by Swanson's Law, which states that the price of solar PV modules decreases by about 20 percent for every doubling in global solar capacity. The law is named after Richard Swanson, founder of high-efficiency solar panel manufacturer SunPower, and indicate a phenomenon seen across many different technologies: new industries face a major learning curve, and as they improve, prices fall. In this way, solar panel manufacturers aren't that different from computer manufacturers. Think about how much more expensive, and less powerful, your laptop was in 2009 compared to the technology that's available today. If solar PV technology continues along the same trend, it's easy to envision a future where solar is on every rooftop

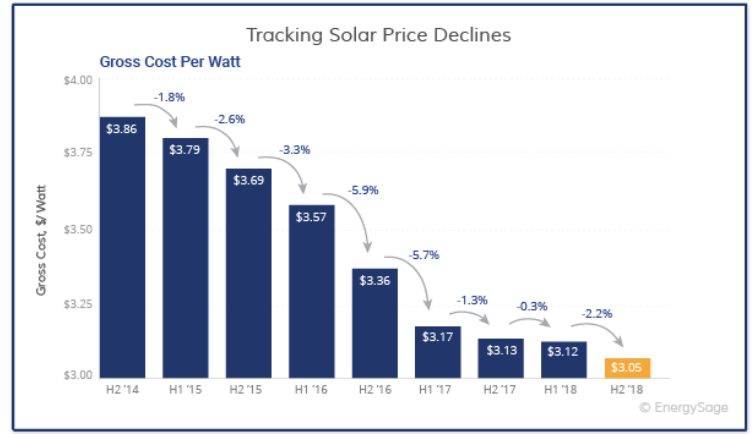

Fig.11 Solar Panel Cost overtime

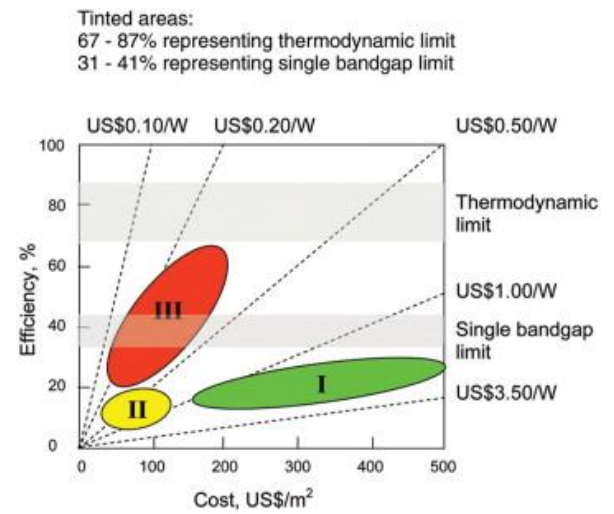

Fig. 12 Efficiency vs Cost projection of PV Cells

\section{PRESENT SCENARIO OF SOLAR PV EFFICIENCY}

Scientists have developed a solar cell that is capable of converting direct sunlight into electricity with 44.5 percent efficiency — making it, potentially, the most efficient solar cell in the world. Current solar technology only converts electricity with a maximum efficiency of about 25 percent. The impressive cell works by stacking multiple layers of solar hardware into a single cell, each of which absorbs a different aspect of the solar spectrum as shown in Figure 13. 
International Journal of Research in Advent Technology, Vol.7, No.4, April 2019

E-ISSN: 2321-9637

Available online at www.ijrat.org

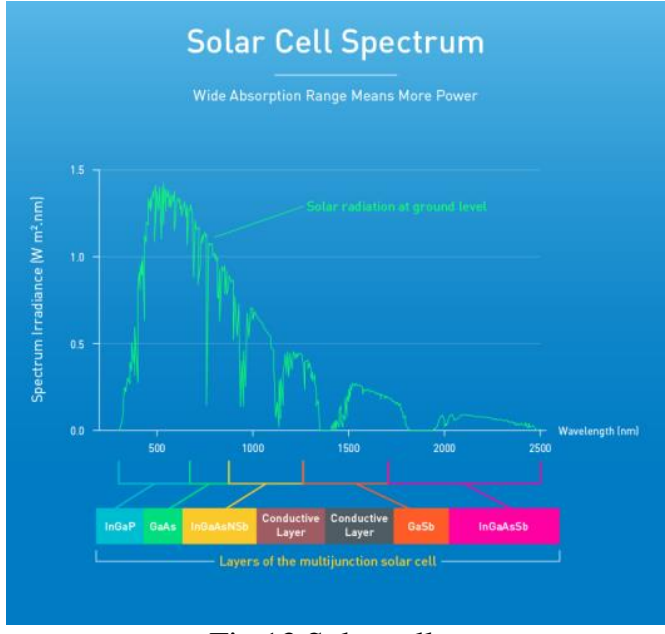

Fig.13 Solar cell spectrum

This new tech is innovative compared to other cells in two regards. First, it uses transfer printing, which allowed the scientists to assemble the component parts with a high degree of precision. Second, it uses materials derived from gallium antimonide (GaSb) substrates, which are usually reserved for infrared lasers and photodetectors, in order to absorb every part of the direct sunlight.

Matthew Lumb, lead author on the study, stated that "our new device is able to unlock the energy stored in the long-wavelength photons, which are lost in conventional solar cells, and therefore provides a pathway to realizing the ultimate multi-junction solar cell."

A perovskites solar cell is a type of solar cell which includes a perovskites structured compound, most commonly a hybrid organic-inorganic lead or tin halidebased material, as the light-harvesting active layer as shown in Figure 14 Perovskite materials such as methylammonium lead halides and all-inorganic cesium lead halide, are cheap to produce and simple to manufacture. Solar cell efficiencies of devices using these materials have increased from $3.8 \%$ in 2009 to $23.3 \%$ in late 2018 in single-junction architectures, and, in silicon-based tandem cells $27.3 \%$ exceeding the maximum efficiency achieved in single-junction silicon solar cells. Perovskite solar cells are therefore the fastest-advancing solar technology to date. With the potential of achieving even higher efficiencies and the very low production costs, Perovskite solar cells have become commercially attractive, with start-up companies already promising modules and power banks on the market by 2017.

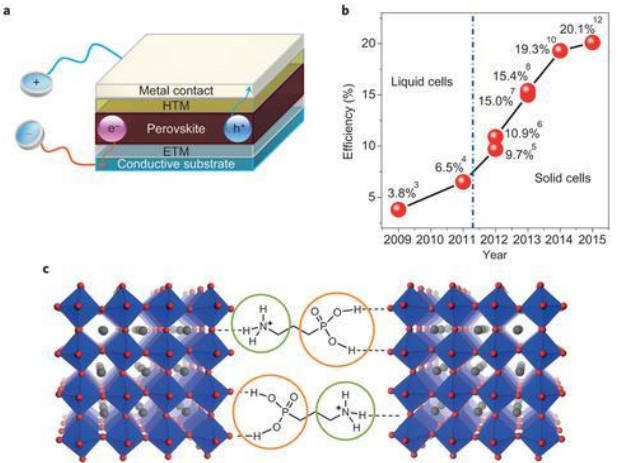

Fig. 14 Perovskite Solar cell structure and Efficiency

\section{THE BOTTOM LINE}

Silicon remains the market leader in photovoltaic systems, and for good reason. Extreme heat, extreme cold, wind, rain and snow don't faze it. By contrast, there is little that won't render a Perovskite cell useless. The compound degrades in water, air and light. Even so, rapid improvements have been made in terms of Perovskite' efficiency, the cost of manufacture, and the range of sizes, thicknesses and colors they come in.

Startups hoping to market emerging technologies will always be optimistic, veterans who have seen these startups come and go will always be skeptical. Which camp is right — or more right — remains to be seen, but investors interested in the future of renewable energy should look out for more news about perovskites. The Figure 11(Appendix - A) shows the NREL (National Renewable Energy Laboratory) Best research cell efficiencies. [6]

\section{CONCLUSION}

First-generation solar cells dominate the market with their low costs and the best commercially available efficiency. They are a relatively mature PV technology, with a wide range of well-established manufacturers. Although very significant cost reductions occurred in recent years, the costs of the basic materials are relatively high. It is not clear whether further cost reductions will be sufficient to achieve full economic competitiveness in the wholesale power generation market in areas with modest solar resources.

Second-generation Thin-film PV technologies are attractive because of their low material and manufacturing costs, but this has to be balanced by lower efficiencies than those obtained from firstgeneration technologies. Thin-film technologies are less mature than first generation PV and still have a modest market share, except for utility-scale systems. They are struggling to compete with very low c-Si module prices and also face issues of durability, materials availability and materials toxicity (in the case of Cadmium).

Third-generation technologies are yet to be commercialized at any scale. Concentrating PV has the potential to have the highest efficiency of any PV module, Other organic or hybrid organic/conventional 
(DSSC) PV They offer low efficiency, but also low cost and weight, and free-form shaping. Therefore, they could fill niche markets (e.g. mobile applications) where these features are required. Thus here in this study highlights the importance new highly efficient cell and impact of the market scenario of cost vs efficiency of PV module.

\section{REFERENCES}

[1] Irena working paper, "Renewable Energy technologies: cost analysis series", IRENA, vol. 1, 2012 , issue $4 / 5$.

[2] Ahmed Hossam Eldin, Mostafa, Abdelrahaman, "A review on Photovoltaic Solar Energy Technology and its Efficiency", Conference: 17th International Middle-East Power System Conference (MEPCON'15), At Mansoura University, Egypt.

[3] Rashmi Swami, "Solar Cell" , International Journal of Scientific and Research Publications, Volume 2, Issue 7, July 20121 ISSN 2250-3153

[4] Green, M. A, " Clean Energy from Photovoltaics ", World Scientific Publishing Co., Hackensack, NJ, 2001.

[5] Dena German Energy Agency, "Information about German renewable energy, industries, companies and product (Federal Ministry of Economics and Technology)", pp. 41, 2013-2014, ISIN: B002MNZE4U.

[6] NREL," Best research-cell efficiency", internet: http://www.nrel.gov/.

[7] Green, M.A. et al, " Solar Cell Efficiency Tables progress in Photovoltaic's: Research and Applications", Vol. 19, 2011, pps 84-92.

[8] G. Zubi, J. L. Bernal-Agust'in, and G. V. Fracastoro, "High concentration photovoltaic systems applying III-V cells," Renewable \& Sustainable Energy Reviews, vol. 13, no. 9, 2009, pp. 2645-2652.

[9] V. Garboushian, D. Roubideaux, and S. W. Yoon, "Integrated high-concentration PV alternative for large-scale solar electric power" Solar Energy Materials \& Solar Cells, vol. 47, no. 1-4, , 1997, pp. 315-323. 
International Journal of Research in Advent Technology, Vol.7, No.4, April 2019

E-ISSN: 2321-9637

Available online at www.ijrat.org

APPENDIX - A

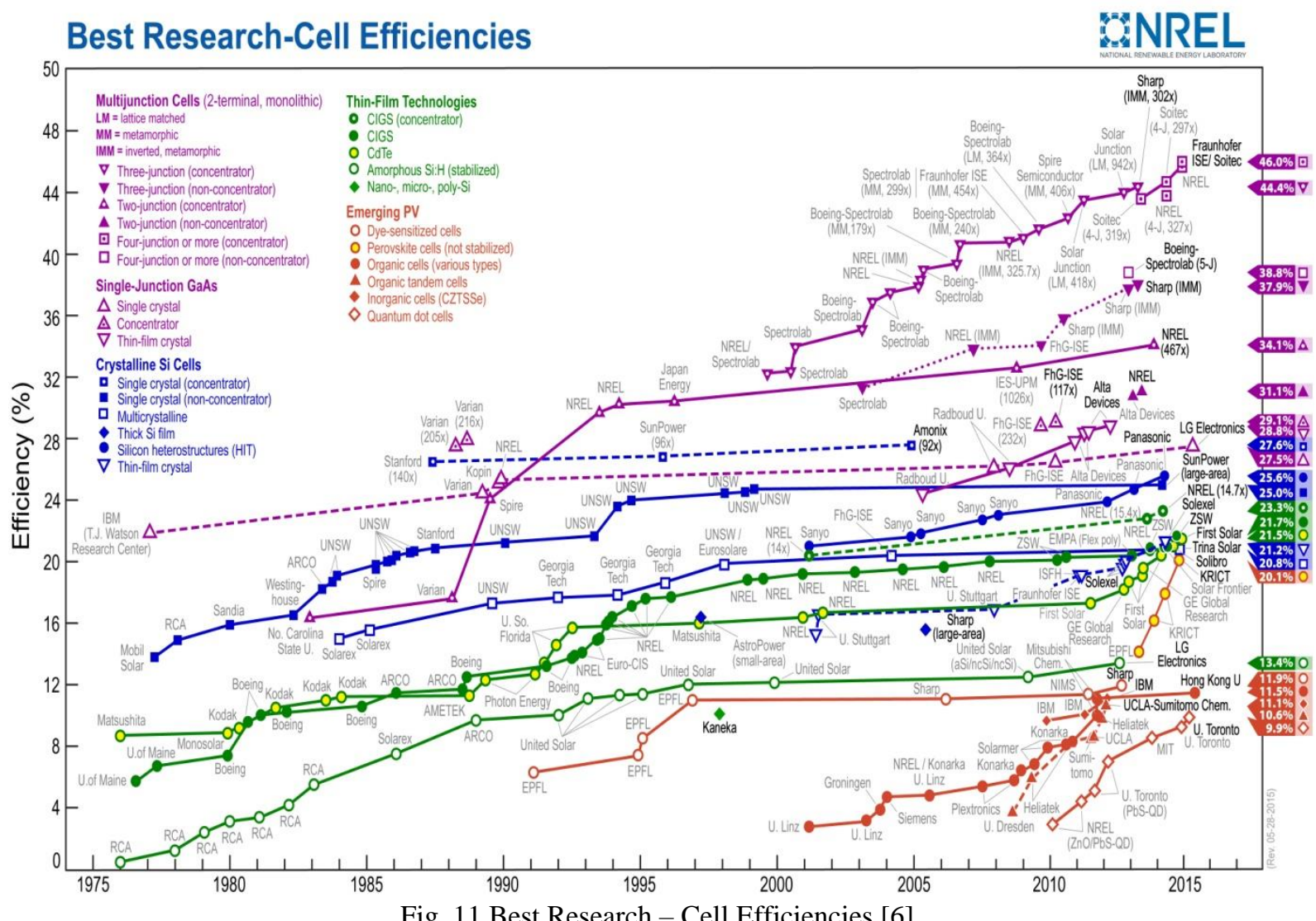

Fig. 11 Best Research - Cell Efficiencies [6] 